\title{
ГЕОИНФОРМАЦИОННОЕ МОДЕЛИРОВАНИЕ РЕЧНОГО БАССЕЙНА ПО ДАННЫМ СПУТНИКОВОЙ СЬЕМКИ SRTM (на примере бассейна р. Терешки)
}

\section{А.Н. Павлова \\ Саратовский государственный университет, кафедра геоморфологии и геоэкологии E-mail: anpgis@rambler.ru}

Статья посвящена вопросам цифрового моделирования территории речного бассейна. В качестве объекта исследования выступает бассейн р. Терешка. Автором приводится подробный алгоритм геомоделирования речного бассейна в среде ArcGIS по данным радарной интерферометрической съемки. Создан ряд моделей, характеризующих рельеф и сток в пределах изучаемой территории. Конечные модели отражают разнопорядковые водосборные бассейны и элементы эрозионной сети.

Ключевые слова: речной бассейн, ГИС-технологии, цифровая модель рельефа, ЦМР, гидрологическое моделирование, SRTM.

\section{Geomodeling of River Basin Based of the Space Data SRTM (as Example of Tereshka River)}

\section{A.N. Pavlova}

This article is devoted to questions of digital modeling of river basin area. The basin of the Tereshka River appears as the research object. The author results detailed algorithm of river basin geomodeling by using of computer software (ArcGIS, ESRI) on the basis of the space data (SRTM). Characterizing relief and water flow models are created. As a result watersheds and stream network are delineated.

Key words: watershed, GIS application, digital elevation model, DEM, hydrological modeling, SRTM.

\section{Постановка проблемы}

Теоретической предпосылкой моделирования геополей в границах речного бассейна служит его выделение в качестве самостоятельной единицы географического пространства [1]. Согласно Ф.Н. Милькову, русло реки и прилегающая к нему территория, с которой оно собирает поверхностный и подземный стоки, в ландшафтном плане образуют сложную природную систему - бассейновую парагенетическую систему [2]. Основной чертой этой системы является упорядоченность входящих в ее состав элементов. Особенно хорошо это видно на примере водного потока, перемещающегося от верховий к устью реки, направленности твердого стока, движущегося вначале от высших точек водораздела в долину реки, а затем вместе с русловым потоком в устье. Подобный характер движения вещества придает бассейну реки динамическое единство как в продольном, так и поперечном планах.

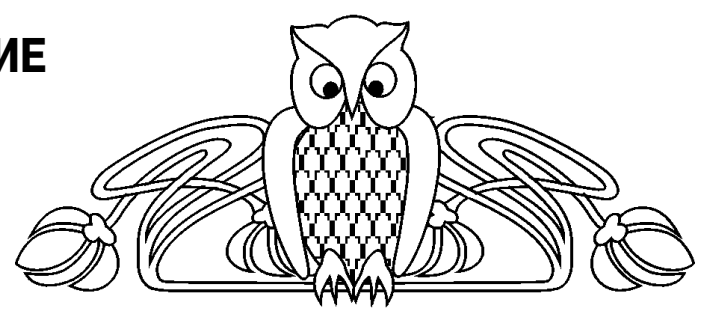

Речные бассейны могут выступать в качестве основной территориальной единицы при районировании территорий, оценке интенсивности эрозионных процессов, в экологических исследованиях. Применение бассейнового подхода географически и экологически обосновано (бассейн - природная и нередко природно-хозяйственная система, экосистема в природных, естественных границах).

Территория в бассейновой модели представлена водосборными бассейнами разного порядка. Главными составляющими водосборного бассейна являются его рельеф и конфигурация сети линий стока. Рельеф выступает в качестве одного из главных факторов стока, так как форма земной поверхности определяет поведение воды. Количественная характеристика бассейна - определение гидрологических и морфометрических характеристик вручную (длина водотоков, положение водоразделов, площадь элементарных бассейнов, угол наклона, расчленение территории и др.) - представляет собой трудоемкую процедуру и требует значительных временных затрат. Традиционным источником данных для расчетов этих параметров являются карты и результаты землемерной съемки. Альтернативный способ получения гидрологических и морфометрических характеристик водосборных бассейнов основан на цифровых представлениях поверхностей, т.е. цифровых моделях рельефа (ЦМР). Автоматизированное получение данных из ЦМР и представление их в виде производных моделей сокращают временные затраты. Такие данные менее субъективны и обеспечивают воспроизводимость результатов в отличие от традиционного «ручного» способа расчетов. Определение дренажной структуры бассейна можно также рассматривать как первый этап в создании гидрологической информационной системы [1].

Целью работы является апробация методики геоинформационного моделирования речного бассейна по данным спутниковой съемки. В качестве объекта моделирования выбран бассейн p. Терешка.

По основным количественным критериям p. Терешка относится к средним рекам (длина реки

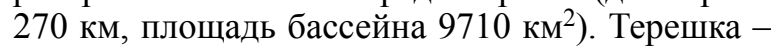
самый крупный правый приток Волги в пределах Саратовской области, впадающий в Волгоградское водохранилище близ с. Усовка. Река берет начало 
и течет в пределах Приволжской возвышенности, в основном параллельно Волге. Основные правые притоки - рр. Лебежайка, Избалык, Алай, Казанла, Карабулак, левые притоки - pр. Елшанка, Маза, Жилой Ключ, Чернавка, Багай, Березовка - в основном имеют небольшую длину в 10-30 км.

В административном отношении территория бассейна реки лежит в пределах Ульяновской и Саратовской областей. Река берет начало на водоразделе рр. Волги и Суры, на юге Ульяновской области. Исток р. Терешка является особо охраняемой природной территорией и имеет статус гидрологического памятника природы регионального значения.

Долина на всем своем протяжении в Саратовской области имеет асимметричное строение. Терешка течет в широкой (1-5 км) долине с крутым правым и более пологим левым склонами. Русло извилистое, в среднем течении берега обрывистые высотой 2-6 м. В среднем и нижнем течении характерны пойменные леса, озера-старицы. В долине прослеживается три уровня надпойменных террас. Первая надпойменная терраса шириной 0,5-1,5 км имеет высоту $40 \mathrm{M}$, развита фрагментарно и обнаруживается в основном по левому склону долины. У р. Терешка также выделяется вторая надпойменная терраса шириной 1-1,2 км и высотой 50-60 м. Третья терраса прослеживается на 134 км из 150 км длины реки в Саратовской области, ширина ее 2-4 км. Поверхность террас слабо наклонена в сторону русла и расчленена многочисленными ложбинами стока, встречаются и суффозионные понижения различной формы [3-5].

Выделим следующие особенности р. Терешки. Река имеет важное хозяйственное значение для административных районов, в границах которых расположен ее бассейн. Воды Терешки используются для орошения и водопотребления. Вместе с тем вода в реке прозрачная, хорошего качества. Долинный комплекс р. Терешки является важнейшим элементом природно-экологического каркаса, выполняя функцию экологического коридора.

\section{Содержание работы}

Как мы отмечали выше, исходным материалом для моделирования бассейнов является цифровая модель рельефа их территории. Растровая ЦМР обладает достаточным объемом информации для определения общего рисунка сети стока и водосборных бассейнов. При этом точность данных, извлеченных из ЦМР в результате ее обработки с помощью гидрологического анализа, зависит от качества и разрешения исходной модели [6]. Основным и относительно недорогим способом получения ЦМР является создание растровой модели по данным, снятым с топографической карты. Однако картам присущ ряд недостатков, связанных со способом изображения рельефа в виде системы изолиний. В данной работе рас- сматриваются возможности использования ЦМР, полученной по данным спутниковой съемки SRTM.

SRTM (Shuttle radar topographic mission) осуществленная в феврале 2000 г. с борта космического корабля многоразового использования «Шаттл» радарная интерферометрическая съемка поверхности земного шара [7]. Данные спутниковой съемки общедоступны и распространяются NASA фрагментами 1 на 1 градус. Файлы данных представляют собой 16-битные растры, где атрибут пиксела соответствует высоте над уровнем моря для данной точки. Исходные файлы могут быть конвертированы в распространенные форматы данных о высотах и затем импортированы в различные картографические программы и геоинформационные системы.

В настоящее время на большую часть земной поверхности доступны ЦMP SRTM 3 (разрешение 3 угловые секунды) и генерализованная версия ЦMP SRTM 30 (разрешение 30 угловых секунд). В данной работе использовались данные SRTM 3 [8]. Применение радиовысотных данных о рельефе является хорошей альтернативой данным, полученным традиционными методами (в особенности данным о рельефе территории, снятым с топографических карт). В работах, затрагивающих вопрос об оценке точности высотных данных SRTM, говорится об их применимости в качестве альтернативного источника информации [9]. В частности, А.В. Погорелов, ряд работ которого посвящен морфометрическому анализу и моделированию бассейна р. Кубани, делает вывод о вполне достаточной точности ЦМР, построенных по данным SRTM, для выполнения распространенных операций морфометрического анализа в масштабном ряду, характерном для исследования типичных геоморфологических объектов, например речных бассейнов [10]. Особо хочется подчеркнуть доступность данных SRTM для широкого круга пользователей. Как мировые геоинформационные ресурсы спутниковые данные о высотах могут служить базой или дополнительным источником информации о самых различных территориях для проведения научных исследований глобального и регионального масштабов.

Моделирование гидрологических характеристик бассейна р. Терешки производилось в среде ArcGIS с помощью инструмента Hydrology, модуля пространственного анализа Spatial Analyst. Предварительно исходные файлы на моделируемую территорию в формате *.HGT были конвертированы в формат *.DEM с помощью программы GlobalMapper 9.0. Затем сшитый растр (грид) высот был импортирован в ArcGIS.

Нами построены базовые морфометрические модели, характеризующие рельеф территории бассейна. Гипсометрическая карта отражает высотные уровни поверхности (рис. 1). В пределах бассейна 


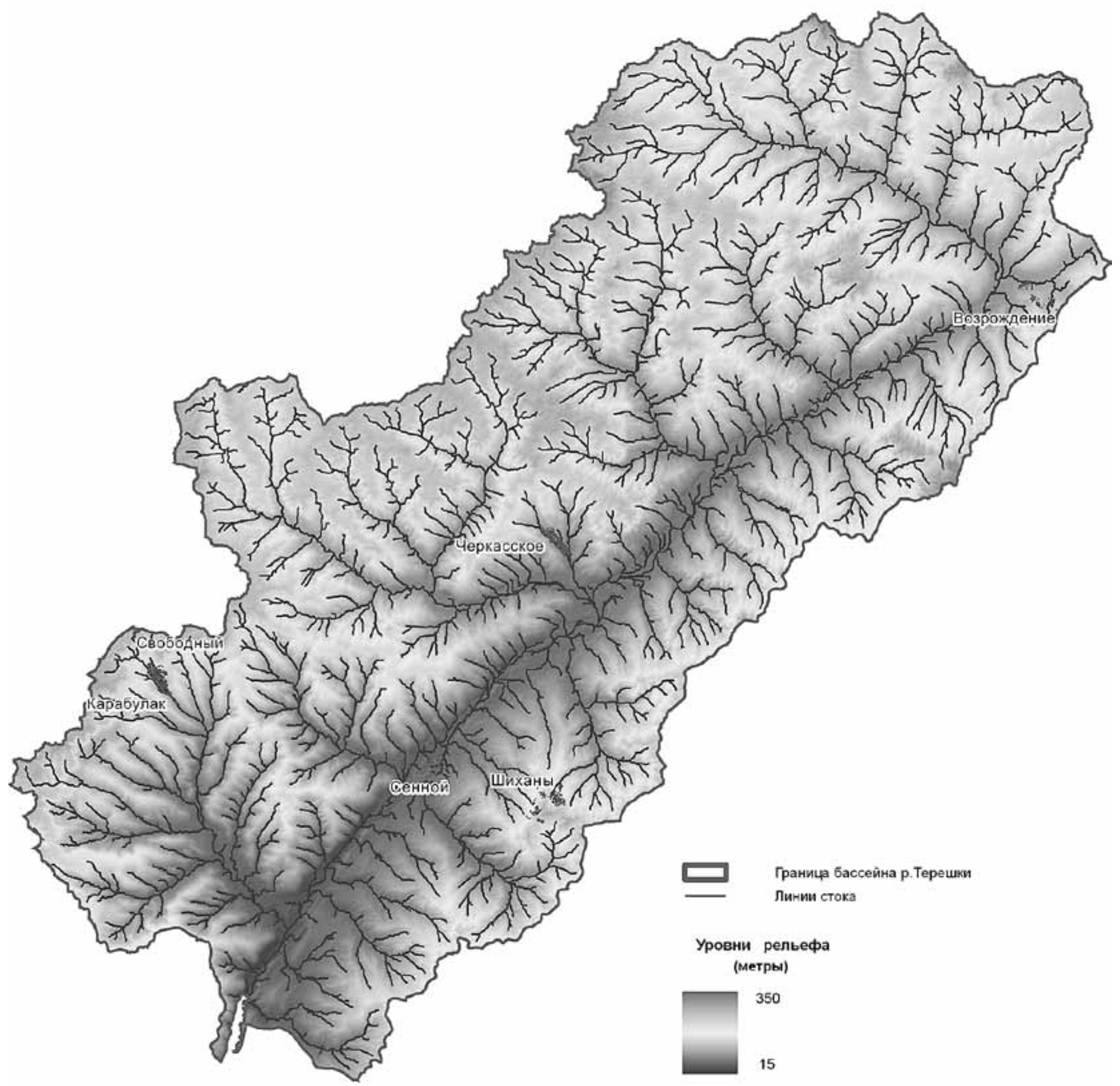

Рис. 1. Гипсометрическая карта

можно наблюдать три древние поверхности выравнивания Приволжской возвышенности (олигоценового, раннеплиоценового и акчагыльского возраста). Анализ показал, что наибольшие площади в бассейне (49\%) занимают участки с абсолютными высотами от 100 до 200 м, преобладают склоновые геосистемы. Наиболее низкие территории с высотами менее 50 м занимают всего $6 \%$ от общей площади бассейна и приурочены к долинному комплексу. На участки с высотой более 200 м приходится $27,7 \%$ площади бассейна, максимальные отметки (более 350 м) в пределах Саратовской области наблюдаются в Хвалынском районе.

Модель углов наклона отражает участки с различной крутизной склона. Более половины территории бассейна р. Терешки (62\%) занимают участки с крутизной склона менее $3^{\circ}$ - это нижние части склонов (41\%) и водораздельные поверхности (21\%). Около 20\% от общей площади приходится на пологие склоны (3-5). Доля покатых и крутых склонов (более $5^{\circ}$ ) также относительно велика - более $15 \%$.
В зависимости от экспозиции склонов все ячейки ЦМР были классифицированы по восьми румбам. В бассейне преобладают склоны южной и восточной экспозиций.

Вертикальное расчленение территории можно охарактеризовать следующим образом: участки с перепадами высот до 5 м занимают около 70\% территории бассейна, с амплитудой расчленения от 5 до 10 м - 20\%, остальные участки имеют большие значения показателя.

Расчлененный характер территории является положительным фактором при моделировании, так как при создании моделей на низменные территории возникает большее количество артефактов (погрешностей).

Далее грид высот был последовательно обработан специальными функциями гидрологического моделирования.

В общем виде алгоритм включает в себя следующие этапы:

1) заполняются некорректные понижения (синки) (функция Fill); 
2) определяются направления стока, т.е. идентифицируются ячейки, в которые будет производиться сток (FlowDirection);

3) рассчитывается кумулятивный сток в каждую ячейку (FlowAccumulation);

4) идентифицируются ячейки водотоков, т.е. выделяются ячейки со значением кумулятивного стока выше значения, заданного пользователем; Link);

5) обозначаются водотоки-звенья (Stream-

6) присваиваются порядки каждому звену эрозионной сети (StreamOrder);

7) определяется дренажная площадь для каждого звена, оконтуриваются водосборные бассейны (Watershed).

Остановимся подробнее на операции расчета кумулятивного стока. Кумулятивный сток рассчитывается на основе поверхности уклона (направления потоков) для каждой ячейки грида. Построенная таким образом растровая модель содержит информацию о водотоках, причем в процессе создания данной модели, используя МаpAlgebra, пользователь имеет возможность задать минимальный кумулятивный сток, который для каждой ячейки определяется минимальным количеством ячеек, стекающих в данную. На выходе мы получим модели водотоков различной степени детализации. Для наших данных оптимальный нижний порог значений FlowAccumulation равен 400. При меньшем значении параметра сеть водотоков содержит значительное количество артефактов, в особенности на выровненных участках. При увеличении нижнего порога кумулятивного стока до 1000 мы получим генерализованную схему структуры бассейна.

Сравнение растровой модели и векторных объектов (линейных гидрографических объектов с топографической карты масштаба $1: 200000$ ) показывает их большое сходство, причем растровая модель является более информативной. Для каждого элемента сети был определен его порядок по методу Хортона-Стралера: за долину 1-го порядка принимается долина, в которую не впадает ни одна долина, при слиянии двух долин 1-го порядка образуется долина 2-го порядка, при слиянии долин 2-го порядка образуется долина

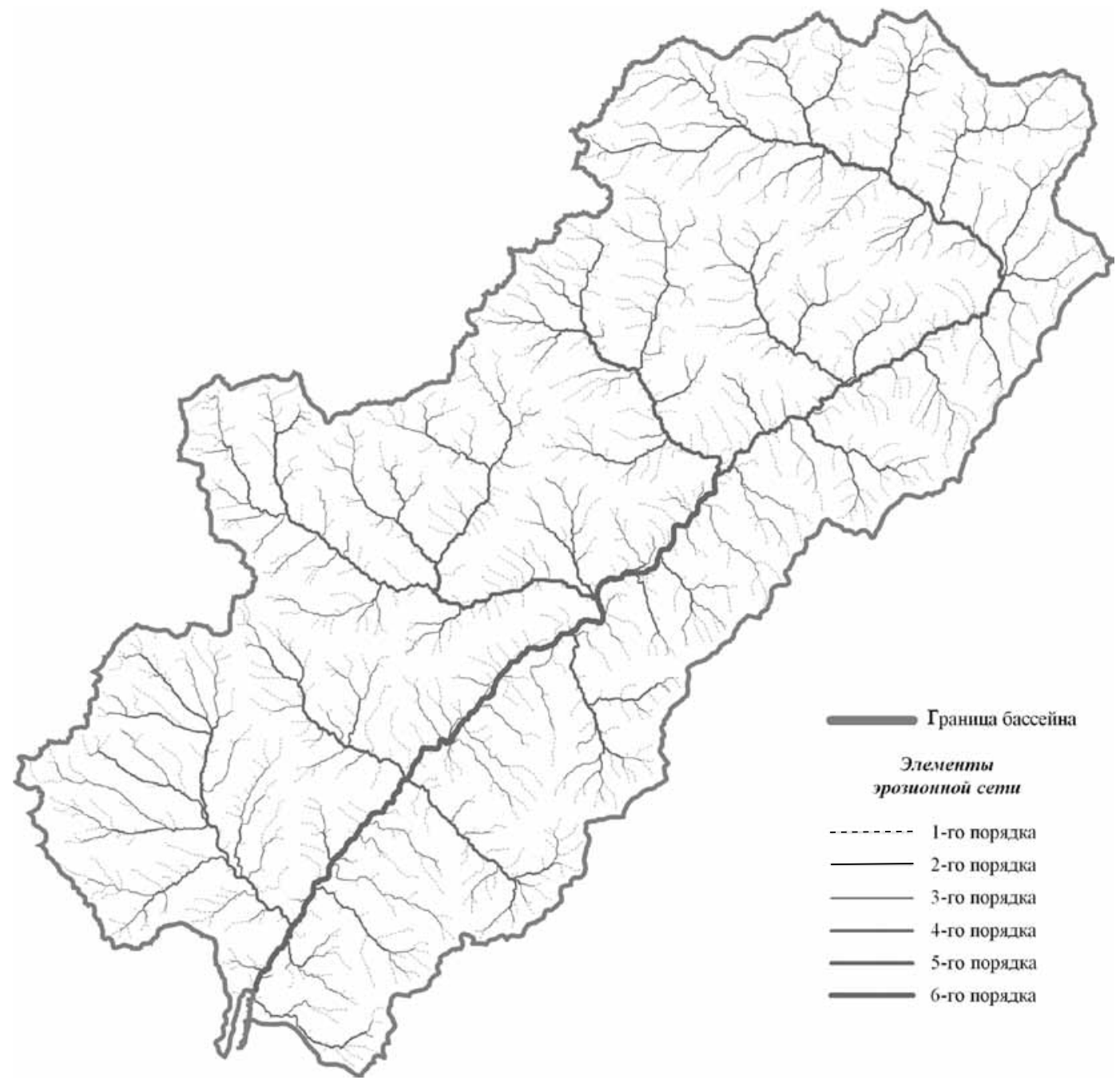

Рис. 2. Эрозионная сеть 
3-го порядка и т.д. (рис. 2). Затем в соответствии с порядком водотока, расположенного в границах той или иной водосборной площади, определялись порядки бассейнов (рис. 3).

На последнем шаге гидрологического моделирования растровые модели сети водотоков и элементарных бассейнов конвертировались в векторные для удаления артефактных полигонов и топологической коррекции.

Всего на территории бассейна р. Терешки было выделено 2470 элементарных бассейнов с 1 по 6 порядки. В пределах бассейна преобладают элементарные бассейны преимущественно 1-го, реже 2-го и 3-го порядков. Среди водотоков 4-го порядка - рр. Кулатка, Казанла, Карабулак, Маза, Чернавка, Багай; 5-го - Алай и Избалык.

Для оценки достоверности результатов моделирования была построена гидрологически корректная модель рельефа на территорию бассейна p. Казанла (правого притока Терешки) по данным о рельефе, снятым с цифровой топографической карты масштаба $1: 50$ 000. Сравнение двух моделей показало их большое сходство. Модель, созданная по данным SRTM, является более генерализованной. Это выражается в значении нижнего порога кумулятивного стока: значение 400 для модели по данным SRTM дает схожие результаты с гидрологически корректной моделью со значением нижнего порога 1000. Таким образом, можно подтвердить пригодность используемых данных для моделирования бассейнов крупных и средних рек. Для проведения более детальных исследований следует использовать источники масштаба $1: 50000$ и крупнее.

\section{Выводы}

По данным радарной спутниковой съемки выполнен комплекс картометрических и морфометрических расчетов. На базе ГИС с использованием автоматизированных процедур построены карты эрозионной сети и водосборных бассейнов на территорию бассейна р. Терешки. Имеющаяся картографическая база и методический аппарат моделирования позволяют в последующем осуществить

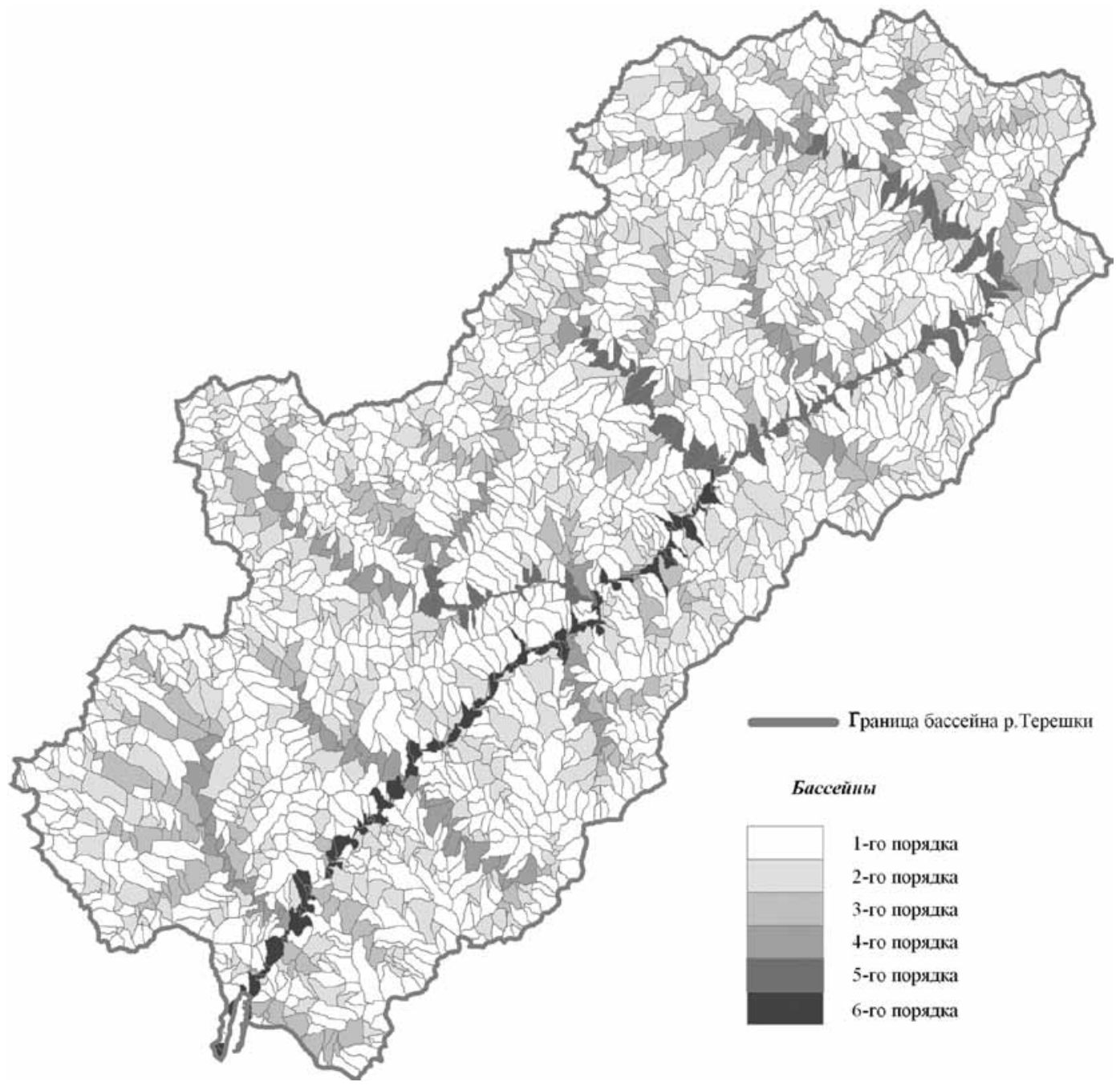

Рис. 3. Водосборные бассейны 
построение карт комплексных морфометрических показателей, базисных и остаточных поверхностей, а также других параметров рельефа. В дальнейшем также планируется применить апробированную методику построения моделей к моделированию бассейнов крупных рек Саратовской области.

\section{Библиографический список}

1. Погорелов А.В., Салпагаров А.Д., Киселев Е.Н., Куркина E.B. Геоинформационный метод в практике региональных физико-географических исследований // Тр. / Тебердинский государственный заповедник. Кисловодск, 2007. Вып. 45. 200 c.

2. Мильков Ф.Н. Бассейн реки как парадинамическая ландшафтная система и вопросы природопользования // География и природные ресурсы. 1981. № 4. С. 11-18.

3. Природа Саратовской области / Под ред. П.С. Кузнецова. Саратов, 1956. 136 с.
4. Проект районной планировки Вольского административного района Саратовской области: В 3 т. Т. 1. Пояснительная записка. Саратов, 1984. 398 с.

5. Энциклопедия Саратовского края (в очерках, фактах, событиях, лицах). Саратов, 2002. 688 с.

6. Maidment D., Djokic D. Hydrologic and Hydraulic Modeling Support with Geographic Information Systems. Redlands, California, 2000. 232 p.

7. Farr T.G., Hensley S., Rodriguez E. at al. The shuttle radar topography mission // CEOS SAR Workshop. Toulouse 26-29 Oct. 1999. Noordwijk, 2000. P. 361-363.

8. ftp://e0srp01u.ecs.nasa.gov/srtm/version2/SRTM3

9. Муравьев Л.А. Высотные данные SRTM против топографической съемки // http://geo.web.ru/db/msg. $\mathrm{html}$ ?mid= 1177761

10. Погорелов А.В., Думит Ж.А. Морфометрия рельефа бассейна реки Кубани: некоторые результаты цифрового моделирования // Географические исследования Краснодарского края. Краснодар, 2007. Вып. 2. С. 7-23.

УДК 528.833

\section{АЛЬБЕДО, ПОГЛОЩЕННАЯ СОЛНЕЧНАЯ РАДИАЦИЯ И УХОДЯЩАЯ ДЛИННОВОЛНОВАЯ РАДИАЦИЯ ПО МАТЕРИАЛАМ АТЛАСОВ NАSА США \\ Ю.А. Скляров, Н.В. Фомина, А.И. Котума, Н.В. Семенова}

Саратовский государственный университет, кафедра метеорологии и климатологии E-mail: kafmeteo@sgu.ru

Приводятся результаты исследований основных составляющих радиационного баланса Земли (РБЗ) на основе данных наблюдений со спутников Nimbus-6 и Nimbus-7, опубликованных в четырех атласах NASA. Изложены результаты анализа широтных распределений альбедо. Предложена методика получения глобальных и полушарных величин альбедо. Показано, что среднеглобальные величины альбедо у ИС3 Nimbus-6 на 5 единиц меньше, чем у ИС3 Nimbus-7 (0,28 и 0,33 соответственно). Обсуждены внутригодовые и межгодовые вариации глобальных и полушарных величин альбедо. По разработанной методике получены данные 0 поглощенной радиации. Выполнен анализ данных об уходящей длинноволновой радиации, в том числе по полушариям. Приведена оценка близости к нулю глобального среднегодового РБЗ.

Ключевые слова: альбедо, поглощенная радиация, уходящая длинноволновая радиация, радиационный баланс Земли, атласы.

\section{Albedo, Absorbed Solar Radiation and Outgoing Longwave Radiation Derived from Data of NASA Atlases}

\section{Yu.A. Sklyarov, N.V. Fomina, A.I. Kotuma, N.V. Semenova}

The results of investigation of main Earth radiation budget (ERB) components derived from the measurement on the Nimbus- 6 and Nimbus-7 satellites and published in four NASA atlases are given. The data of latitudinal albedo distribution are described. The methodic for receiving of global and hemisphere values of albedo is proposed. It is showed that global averaged albedo values from Nimbus- 6 satellite are less than from Nimbus-7 at 5 albedo units $(0,28$ and 0,33 correspondingly).

The annual variations of global and hemispherical albedo values are discussed. The absorbed radiation data were received and peculiarities of their variation are given. Analysis of data about outgoing longwave radiation was fulfilled. Evaluation of proximity to zero of global annually averaged ERB was made.

Key words: albedo, absorbed solar radiation, outgoing longwave radiation, Earth radiation budget, atlases.

В Саратовском государственном университете несколько десятилетий ведутся работы по исследованию компонентов радиационного баланса Земли (РБЗ). Разработанная аппаратура для измерений уходящей коротковолновой радиации (УКР) и солнечной постоянной (главный конструктор профессор Ю.А. Скляров) работала на высотных аэростатах [1], на трех ИС3, в том числе на двух в совместных российско-французских проектах $[2,3]$. Получен большой объем данных. Практически завершена обработка наблюдений с ИСЗ «Метеор-3» № 7 и «Ресурс-01» № 4. Завершается подготовка материалов атласа наблюдений УКР, альбедо и поглощенной солнечной радиации по материалам наблюдений с ИСЗ «Ресурс-01» № 4 (получено более 86000 наблюдений). Рассмотрены вопросы построения карт распределений, получения среднесуточных величин альбедо, наблюдаемости поверхности Земли с гелиосинхронных ИСЗ [4-6]. Завершено изготовление 